\title{
Gonorrhoea in a toddler: sexual abuse or accidental infection?
}

\author{
Roger Higgs Editor
}

\section{Case Conference Editor's note}

\begin{abstract}
Discussion of the issues is edited by Fohn Harris, Paul Hodgkin and Mary Lobjoit for the Manchester Medical Group.

This is the first case conference from a medical group. Further cases of this type would be welcomed.
\end{abstract}

\section{Case history (from the general practitioner)}

Janey is two and a half years old and is the first child of Mary (aged 21) and her husband (aged 22). Mary herself is the second of three girls. Her mother had died in 1978 of breast cancer and since then Mary and her two sisters had lived at home with their father, Jack. Mary's elder sister Pauline had acted as surrogate mother to the other two sisters, but Pauline moved away, just after Janey was born, to have a child of her own. Four years ago both younger sisters had complained to the practice about their father 'harassing' them, by which they seemed to mean that he expected them to come home at what they thought to be an unreasonably early hour, and threatened them with violence about their boyfriends. At the time this problem was discussed at some length with the girls but thereafter was never brought up again. At no time was there any complaint about sexual abuse. It was clear, however, that Jack did have a considerable drink problem. Although a patient he has not attended since 1977. Up until the time of Janey's illness the whole family lived in Jack's run-down two-bedroom house in the inner city.

Attention was first brought to Janey's problem when Mary brought her to see the health visitor, saying that Janey had been quite well until the previous night when she had woken up screaming. The next morning Mary noticed Janey had a vaginal discharge which was very slightly blood-stained and brought her immediately to the practice. As her GP I was asked to see her. When I came into the room Janey was sitting quietly on the couch next to her mother but after some initial quesitons I approached her to examine her and without any encouragement being needed she lay back and opened her legs. My impression was that this was definitely not the first time a man had asked her to do this. Since she did indeed have a profuse discharge (though this was not blood-stained) she was admitted to hospital straightaway under the care of a. paediatrician. Gonococcus was subsequently grown ${ }_{\mathcal{O}}^{\text {N }}$ from both Janey and Mary but from no one else in the $\stackrel{-}{-}$ family.

The paediatrician interviewed Mary who said it had not been unusual for Janey to be cared for overnight by $气$ Mary's father or a 15-year-old male cousin who alsoळ stayed there from time to time. When both Janey and $\vec{c}$ the 15-year-old boy were staying, Mary said, they usually slept in the same bed because of shortage of space. Mary also said that over the previous fewo months she herself had had another 'boyfriend' although this was not known to her husband. The paediatrician explored whether Mary wanted the $\frac{\mathscr{Q}}{\not}$ police involved and at her request the police were $\varrho$ called in and subsequently interviewed everyone in the $\overrightarrow{\vec{O}}$ family.

The advice of a venereologist was sought and he said? that in his opinion it would have been possible, if $\stackrel{\text { ? }}{-}$ unlikely, for Janey to have acquired the infection from $\overline{3}$ her mother during their regular baths together. In view of this and the fact that no other gonococcal contacts were picked up in the family no criminal charges were made and the source of Janey's infection was nevero found. Within a few weeks Mary, her husband and Janey moved out to homeless families'은 accommodation. No case conference was held because the police, as I understand it, would not allow a conference whilst there was any possibility of criminal charges being laid. Consequently, follow-up was left $N$ with the primary care team and the senior social worker from the hospital.

However, an informal case conference was later convened by the Manchester Medical Group to discuss 0 the ethical issues raised by Janey's case. The chairman was a senior general practitioner and those taking part were Janey's GP, the health visitor, the consultant paediatrician and the medical social worker who had $\vec{\Phi}$ been involved, and a lecturer in philosophy.

\section{Should the police be involved?}

Since Janey might well have been the victim of sexual assault or abuse, whether incestuous or not, and at the very least must be considered to be likely to have been $\frac{\bar{\alpha}}{\partial}$ 
the victim of a non-accidental injury, all were agreed that the police had to be involved in this case although views about the desirability of this involvement differed widely. The reason for these differences was summed up by the GP who noted that the groups involved in the case all had different aims. "The police will be principally concerned with ascertaining whether or not a crime has been committed and if so in apprehending the criminal. The paediatrician will be much more child-centred, the social worker will often (although not necessarily in this case) be family centred'. Having noted these differences the GP agreed with the philosopher that, however inevitable, the police contribution here might well be unhelpful from the point of view of the interests of Janey and her family. The paediatrician said he had seen four similar cases in the previous six months. He felt that an important problem which arose from the necessity of involving the police in cases of this sort was that families who needed help might well be prevented from seeking it for fear of the consequences. Also the trauma of police investigation might prove detrimental to the child and to the future of the family. Since the police investigation was eventually abandoned because the transmission of infection could have been accidental, the philosopher wondered whether the involvement of the police might not have been premature. If the medical opinion was that there was an innocent explanation, was it right to be so clear in suspecting the family and subjecting them to a considerable ordeal? The GP pointed out that the reality was that it had not so much become clear that the infection was, or was probably, accidental but rather that a hole had been shot through any case that might come to court in that the defence could offer an alternative and entirely 'innocent' explanation of the alleged offence. It was this fact that lead the police to abandon the investigation. The chairman remarked that this raised one of the central themes of the case: should those involved be ready to rationalise and to accept that, because there was a possibility that the transmission of infection was innocent, this might reasonably be accepted as the true explanation of the infection?

\section{Is incest important?}

The philosopher suggested that the question of whether or not incest was involved was a red herring, since most doctors and social workers would not consider involving the police if they discovered incest between consenting adult patients. The crucial issue was that the child had probably been the victim of an assault in circumstances where the proximity of the guilty party would make repetition likely and protection of the child difficult. The chairman felt that one important difference in this case was that Janey had contracted an infection and that this was a personal injury and one in which it was proper to involve the police. The philosopher suggested there might be many circumstances in which members of a family inflicted injury or disease on one another by their mere proximity, and that it was not so much the issue of disease that so to speak licensed the intervention of the police here, but the suspicion that it had been inflicted as a result of an illegal assault.

\section{Consent to investigation}

The paediatrician emphasised that a written and witnessed statement of consent to investigation was always obtained before formal investigations began and in this case was obtained from the mother. The philosopher wondered how genuine this consent could be when the mother knew that the family (and perhaps herself) were under suspicion of being involved in a serious criminal offence. If she refused would not the investigation proceed in any event but with more suspicion falling on her and possibly more unpleasantness accruing to the family? Wasn't it rather a case of 'will you consent to rape or shall I rape you'? The medical social worker reminded the group that the police were likely to be very discreet; that the officers came from a special section used to dealing with delicate cases, and that they were always aware of the need to look at the whole picture.

\section{The lack of clarity}

The GP noted how difficult it had been in this case to be clear about what had actually happened. There was both a physical and psychological obscurity where incest was concerned, especially where it involved very young children. The physical events which actually occurred might be very uncertain whilst psychologically many family members might be reluctant to reveal either their knowledge or their suspicions. In this particular case there was also a technical obscurity about where the gonococcal infection really came from - was it an 'incestuous' or an 'innocent' infection? The willingness of all participants to clamber aboard the 'innocent' explanation with such a mixture of relief and guilt reflected all this ambiguity, together with the psychological unpleasantness of contemplating incest.

\section{What's best for Janey?}

While all were agreed that Janey's best interest should be the paramount consideration there was some doubt about how this could best be achieved. The philosopher said he had subsequently gathered that when Janey was first examined she had shown no sign of distress and yet later, after much investigation, both medical and criminal, she was distressed when medically examined. He wondered whether in terms of psychological damage her exposure to investigation and to the 'shock horror' reaction of adults should not have been minimised even at the cost of failure to find those responsible. The health visitor on the other hand was clear that the investigation should not have been abandoned when it was and that more investigations 
should have taken place.

All felt that some more structured follow-up, in which an unobtrusive and benevolent eye could be kept on the family and on Janey's safety, was desirable and should not end now, just because the police investigation had been abandoned. The paediatrician felt the family had strengths which enabled him to allow Janey to be discharged back into its care. The GP felt it came down to a balance between two judgements: was Janey assaulted and if she was how was she harmed by both the event and the subsequent investigations? It was most probable that she had indeed been assaulted, but whether her best interests had been served by either the police involvement or the ease with which all the participants accepted an $\Rightarrow$ alternative, innocent explanation was doubtful. That $\stackrel{5}{\rightarrow}$ she had been harmed was beyond doubt since even if $\bar{c}$ caught from her mother, the gonococcal infection might well ultimately affect her fertility. Also, the GP $\frac{\bar{\sigma}}{\vec{D}}$ added, the investigation and examinations would have $\propto$ left their mark. Certainly Janey's interests were not क served by the failure to hold a case conference.

\section{News and notes}

\section{Research spending on disease and its treatment reaches $\$ 600$ million}

Expenditure on medical research has reached $£ 600$ million. According to a recent Office of Health Economics report: Pharmaceutical Innovation: Recent Trends, Future Prospects, more than $£ 600$ million was spent on investigating disease and potential new treatments in Britain in 1982. The report also identifies the pharmaceutical industry as the major contributor to today's record level of spending: in 1982 the industry allocated $£ 419$ million to its research and development programme.

Yet in spite of sustained increases in research funding, the OHE analysis shows that there has been no corresponding growth in the output of new medicines. Indeed the reverse has been the case. An average of only 20 new chemical entities now become available each year compared with twice that number in the early 1960s. The report notes that this trend has been a world-wide phenomenon.

The OHE argues that the primary explanation for this development is the soaring cost of transforming a laboratory chemical into a prescribable medicine.

Today the average cost of developing a new medicine by a pharmaceutical company is between $£ 50$ million and $£ 90$ million over a period of 10-12 years.

The OHE emphasises, however, that despite this trend, a number of highly innovative new medicines have appeared in recent years. In the cardiovascular field - which accounts for 22 per cent (or $£ 260$ million) of the total cost of drugs prescribed by family doctors - the development of calcium antagonists and special enzyme inhibitors represent major advances in therapy for heart disease and high blood pressure. New medicines are available for treating ulcers which can avoid the need for hospital admission, now costing as much as $£ 500$ per week. Finally, without drugs such as cyclosporin, the new era of life-saving transplant surgery would not be possible.

Nevertheless, the OHE is concerned that a continuation of recent trends might deny society the therapeutic promises suggested by current research efforts. Advances, for example, in understanding the role of the body's chemical messengers neurotransmitters and regulatory peptides - herald the possibility of new therapeutic approaches to mental disorders (such as dementia and schizophrenia) as well as more effective control of pain. And immunological research is progressively unravelling the complexities of the body's natural defence system, thereby paving the way for devising treatments for a wide range of viral, autoimmune and other disorders.

The OHE report makes it abundantly clear that such progress is urgently needed: 30 per cent of the population suffers from long-term and frequently disabling ill-health. Among people aged $65-74$ years this proportion rises to 50 per cent. In many instances cardiovascular, mental and arthritic disorders are the cause of impairment.

Focusing on mortality, the report notes that one death in four (that is, approximately 130,000 fatalities each year in England and Wales) is of someone who has not celebrated his or her 65 th birthday. The OHE's analysis suggests the solution to premature mortality lies principally in healthier lifestyles. Yet it is clear that new medicines could play a valuable role. In cancer, new drug combinations, better understanding of cancer cell survival strategies and the discovery of oncogenes offer the prospect of new therapeutic interventions.

In addition some of the burden of premature coronary mortality -35 per cent of adult male deaths before 65 years stem from this cause - might yield to pharmacological measures. Scientists are beginning to understand the chemistry underpinning the balance between free and restricted blood flow.

Looking to the future, the OHE argues that government has a major role to play in facilitating the evolution of innovative new medicines. It must make available adequate funds for medical research undertaken in academic centres. It must also ensure that the regulatory and economic environment within which the pharmaceutical industry has to operate is consistent with innovation as a realistic commercial objective. The industry is the essential vehicle of new drug development and without appropriate support the predicted therapeutic breakthroughs are unlikely to be realised. 